\title{
Harnessing Drag Energy in Electric Automobiles
}

\section{Mr. Aman Luthra, University of Georgia \\ Dr. Tom Lawrence P.E., University of Georgia}

Dr. Lawrence is the program lead for mechanical engineering at the University of Georgia. He has over 35 years of professional experience, roughly half of which was in industry and the latter half now in academia. He has been the primary point of contact between the University of Georgia and Karlsruhe Institute of Technology and the industrial corporate partners for advancing this program.

\section{Dr. John M Mativo, University of Georgia}

Aman Luthra is an undergraduate at the University of Georgia. He is a Mechanical Engineering student interested in Energy Harvesting.

Dr. John Mativo is Associate Professor at the University of Georgia. His research interest lies in two fields. The first is research focusing on best and effective ways to teaching and learning in STEM K16. He is currently researching on best practices in learning Dynamics, a sophomore engineering core course. The second research focus of Dr. Mativo is energy harvesting in particular the design and use of flexible thermoelectric generators. His investigation is both for the high-tech and low tech applications. In addition to teaching courses such as energy systems, mechanics, mechatronics, and production, he investigates best ways to expand cutting edge technologies to the workforce. 


\section{Improving the overall efficiency of electric vehicles by}

\section{harvesting drag energy}

\section{Abstract}

The following research project investigated a novel method of harvesting drag energy in electric automobiles for conversion into supplemental electric power for the vehicles. The main focus of the project was on capturing drag energy in the vehicle's compartment, where some airflow is needed for cooling purposes but most is wasted as drag. The project entails estimating the potential of mounting a rotating fan blade attached to a generator in the vehicle's engine compartment, which would spin as the vehicle is in motion and generate extra power for the vehicle's battery. To evaluate this potential, an anemometer and logger were mounted in the compartment of a Ford C-Max Plug-In Hybrid to estimate how much electrical power could be generated at various speed limits. Data was collected from a sample trip that included local roads and highway travel. From the data collected, an equation was generated to show the correlation between driving speed and power generated. The results showed that the drag-energy-capturing system would generate enough power to increase the vehicle's battery life by an average of $0.1 \%$ at full capacity. While an economical product cannot be made based on these results, it will still be helpful to investigate such an idea further. We identified multiple areas for improvement including a refined experimentation and measurement process and system designs that can increase the system's power-generating capability and ultimately reduce emissions from vehicles.

The paper is a result of a yearlong honor's course. The student and faculty that conducted the research created methods of investigation that enabled them to generate data and analyze it. The methods are presented as a reference point for future research.

Introduction

The course MCHE $4960 \mathrm{H}$ is a one credit hour per semester directed study offered as an independent laboratory research and design for mechanical engineering students at the Center for Undergraduate Research Opportunities (CURO) engineering program. Research is done under the direction of an engineering faculty member. CURO promotes sustained, progressive, and faculty-mentored research opportunities for UGA's undergraduates. CURO Honors Scholars receive \$3,000 in funding each year, enjoy mentoring and community support, and attend special seminars, workshops, events, and activities. CURO Honors Scholars pursue their own research agenda in their first semester at UGA, and they can conduct research in any discipline at UGA, 
including (but not limited to) physical, biological, and social sciences as well as business, international affairs, engineering, humanities, and the fine and performing arts [1].

In this project, the student proposed to design and study how to make electric vehicles more efficient in terms of investigating novel methods for increasing energy recovery for the recharging of the battery or power accessories such as a radio. The plan entailed capturing a portion of drag in the engine compartment and using it to generate additional electrical energy by placing a rotating fan blade in the compartment of a vehicle and attaching it to a generator. The fan blade would spin as the car was driving, and the student would calculate how much additional power it could generate.

At the beginning of the first semester of the project, the student and two engineering faculty mentors with expertise in energy recovery met and developed a timeline for the study. The first semester would focus on planning the experiment and collecting pertinent materials. The second semester focused on conducting the experiment and analyzing data. The last semester focused on an economic analysis as well as reflections, drawing conclusions, and applications.

\section{Motivation}

In 1950, the global atmospheric $\mathrm{CO}_{2}$ concentration reached over 300 parts per million, the highest on record at the time. Since then, the concentration has surpassed 400 parts per million and is continuing to increase [2]. Because of increasing $\mathrm{CO}_{2}$ emissions, as well as those of other greenhouse gases, climate change continues to drive major environmental issues including rising sea levels, more destructive hurricanes, and more prolonged droughts [2]. One major contributor to the increase in greenhouse gas emissions has been from driving $\mathrm{CO}_{2}$ vehicles. An average $\mathrm{CO}_{2}$ car emits over 11,000 pounds of carbon dioxide per year. However, an average electric car emits only 4,300 pounds per year [3]. As the global energy demand continues to increase, so does that of electric vehicles, but one significant challenge with electric vehicles is lower mileage when compared to gas-powered cars. Research for electric vehicles is being done to improve aerodynamic efficiency, improve battery composition, capture wasted braking energy, and so on. However, little thought has been given to help harvest wasted drag energy in and around electric vehicles. The study in the paper aims to fill that gap and provide insight into harvesting wasted drag energy in the compartment of an electric vehicle.

One method to investigate the potential of harvesting wasted drag energy has been to install compartments on the top or side of a train, put a rotating turbine inside that spins as air flows over it and inside the compartment, and attach the turbine to a generator that produces additional electrical power for the train [4]. Although this strategy may be effective in producing extra power and saving money in the long run, some challenges with the design are that it creates additional drag being on the outside of the vehicle and that the efficiency of the system heavily 
depends on environmental factors such as the route that is being taken, wind trajectories, elevation, etc. [5]. Therefore, the proposal in this paper is to place a turbine and generator inside the compartment of an electric vehicle where drag is directed through the grill of the engine compartment and is considered wasted. As part of an undergraduate research course, the student, with help from mentors, will design a system to harvest a fraction of that drag energy and resupply it to the vehicle battery for additional power. Capturing this drag energy could cater to the growing demand for electric vehicles with its ecological and economic benefits.

There are three main goals for the research course, which are to investigate the potential of generating power by capturing drag energy in a vehicle's compartment, to explore locations in the compartment for the most airflow, and to conduct an economic analysis of a drag-energycapturing system in the vehicle compartment. Achieving these goals will help the student develop an initial viewpoint of capturing wasted drag energy in a vehicle and how doing so can help increase the energy capacity of batteries in electric vehicles.

Method

To conduct the experiment, the research student mounted an anemometer with a logger in the compartment of a 2017 Ford C-Max Plug-In Hybrid with zip ties and painters' tape and drive on local roads plus highways as the anemometer and logger would record air velocities in the vehicle's compartment. A Model VT-300 Miniature Vane Thermo-Anemometer [6] was used for the experiment. From a front view of the vehicle, the anemometer and logger were mounted in the lower left side of the compartment, shown in Figure 1, and in front of an air intake point needed for cooling purposes, shown in Figure 2, since consistent airflow was expected.

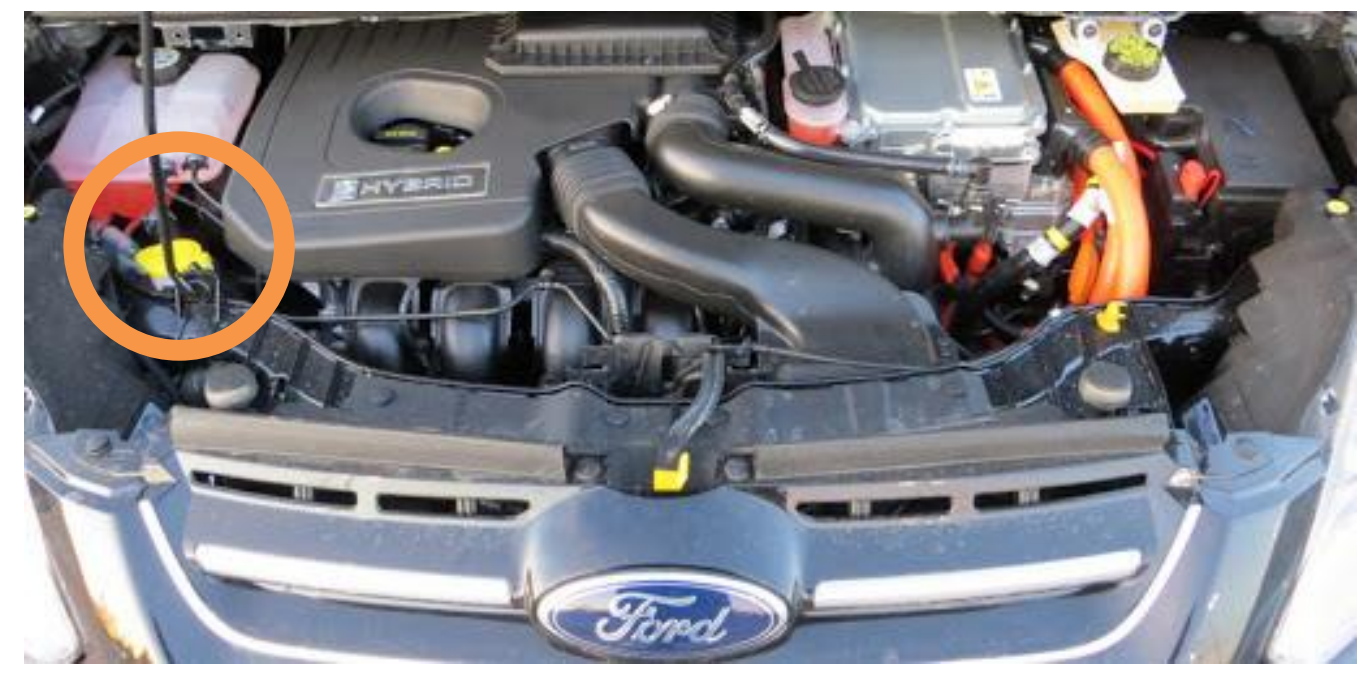

Figure 1: Mounting Location in Ford C-Max Compartment 


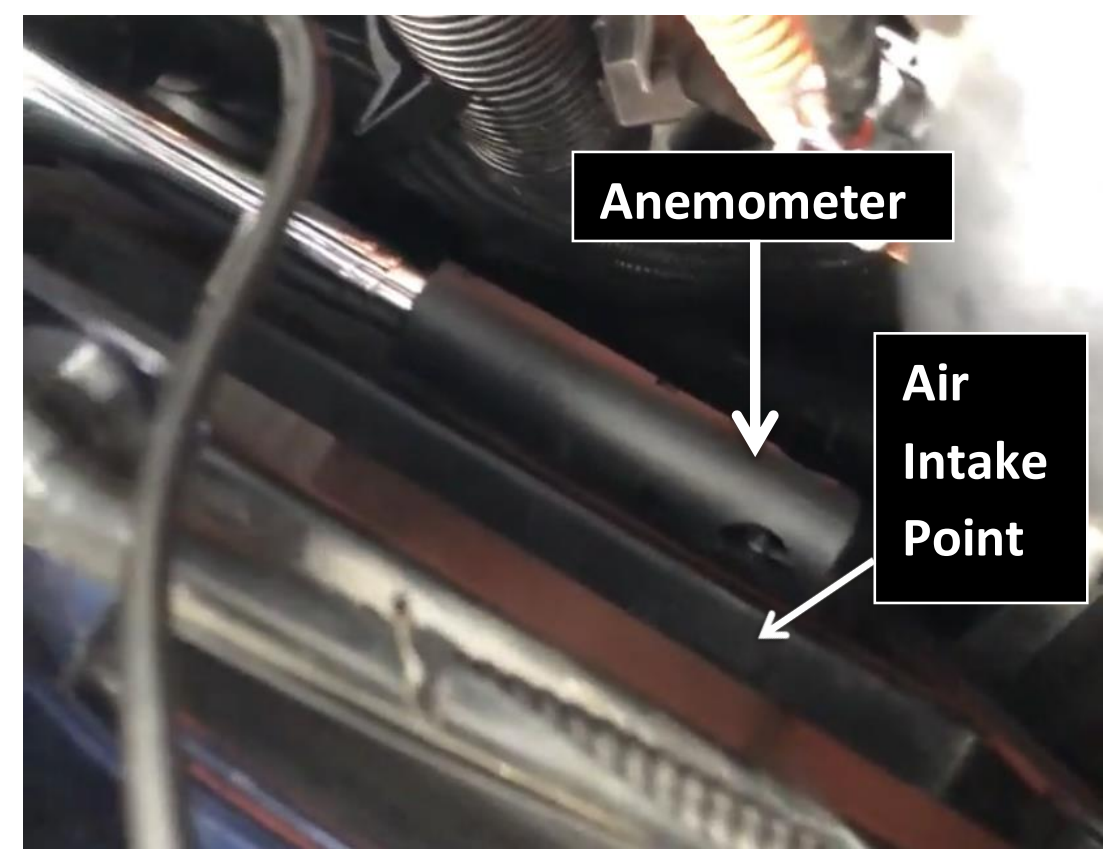

Figure 2: Anemometer mounted in the compartment

With the recorded air velocities in the logger, the power generation equation was then utilized to calculate the output of a theoretical turbine-generator system. It was assumed that the air density would be equivalent to that at sea level $\left(1.23 \mathrm{~kg} / \mathrm{m}^{3}\right)$, the area swept by the blades was on a square-meter basis, and that 0.4 was the coefficient of performance [6]. Next, the power outputs were then multiplied by five-second time intervals, which are what they were recorded at, to be converted into energy outputs. The energy output values were then correlated with the driving speeds by relating average speeds with average energy outputs. With the correlation, a third-order equation, which corresponds to the velocity input of the power generation equation, was created to show the energy output, in $\mathrm{kWh}$, as a function of driving speed, in mph. Finally, an economic analysis was conducted to evaluate how long it would take for the theoretical system with a turbine, generator, wires, etc. to overcome its cost of production by generating additional power for the vehicle as opposed to conventional charging. These steps allowed the research student to gain a full understanding of how professional scientific research can be done to go from an idea to a potential engineered product.

Results

Figure 3 displays the vehicle's driving speed, converted into meters per second, during the test drive versus the recorded air velocity in the anemometer. A total of 183 readings were taken over the test drive with five-second gaps between each recording. With the data collected, the data was then divided into sixteen sections which corresponded to speed-limit changes 
between roads along the driven route. These sections are highlighted in Figure 2 by sudden drops and spikes of the car velocity where a stoplight, stop sign, or turn was encountered. The recorded readings were grouped 1-8, 9-18, 19-25, 26-34, 35-45, 46-66, 67-85, 86-103, 104-124, 125-130, $131-133,134-149,150-158,159-165,166-173$, and 174-183 to make up the sixteen sections.

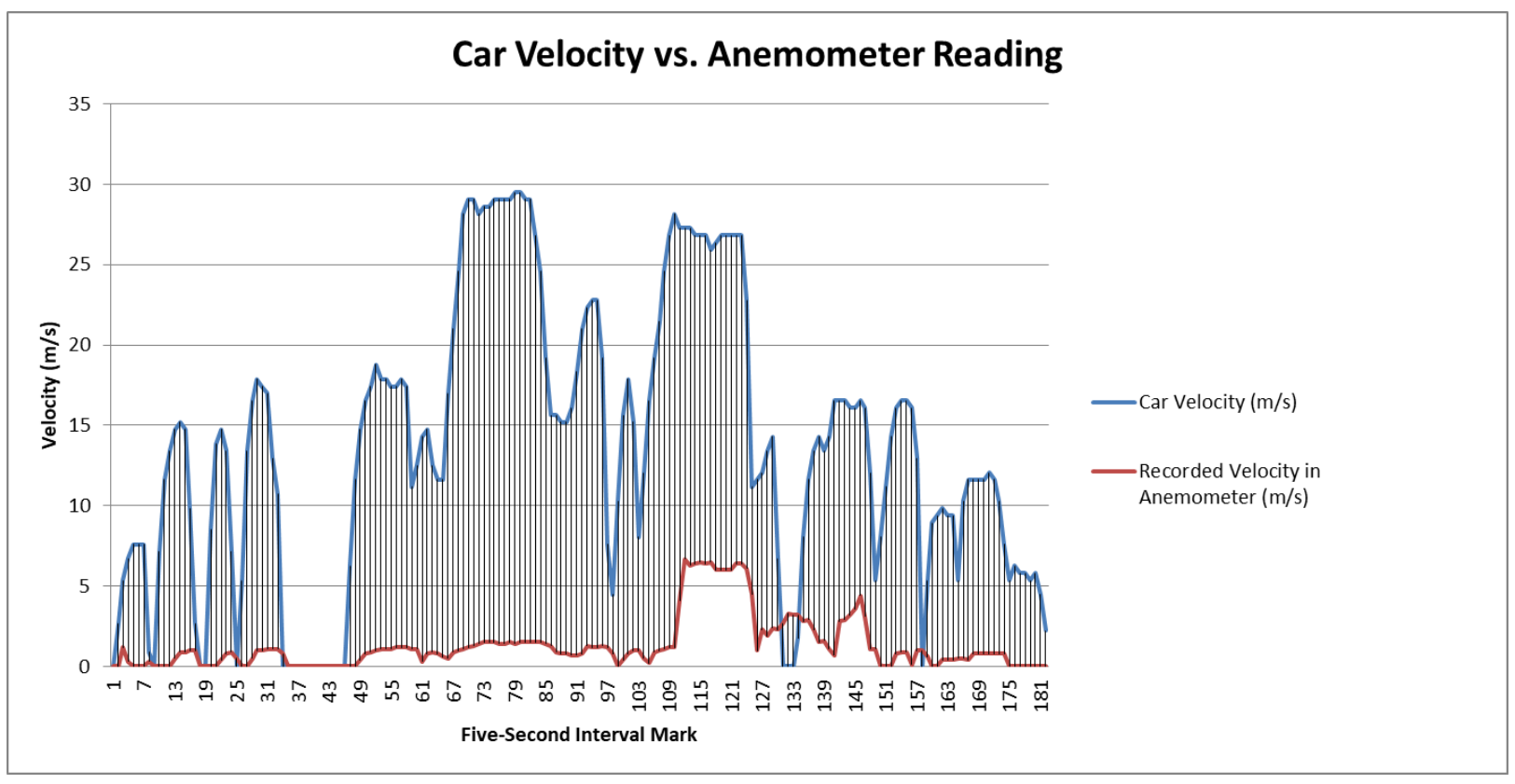

Figure 3: Car velocity $(\mathrm{m} / \mathrm{s})$ versus anemometer reading $(\mathrm{m} / \mathrm{s})$

In Figure 4, the average car velocities of the readings in each section, shown as blue markers, were calculated and plotted versus the average air velocity recorded in the anemometer of each section, shown as red markers. The plotted values are in chronological order from left to right with respect to the recorded data in the test drive. 


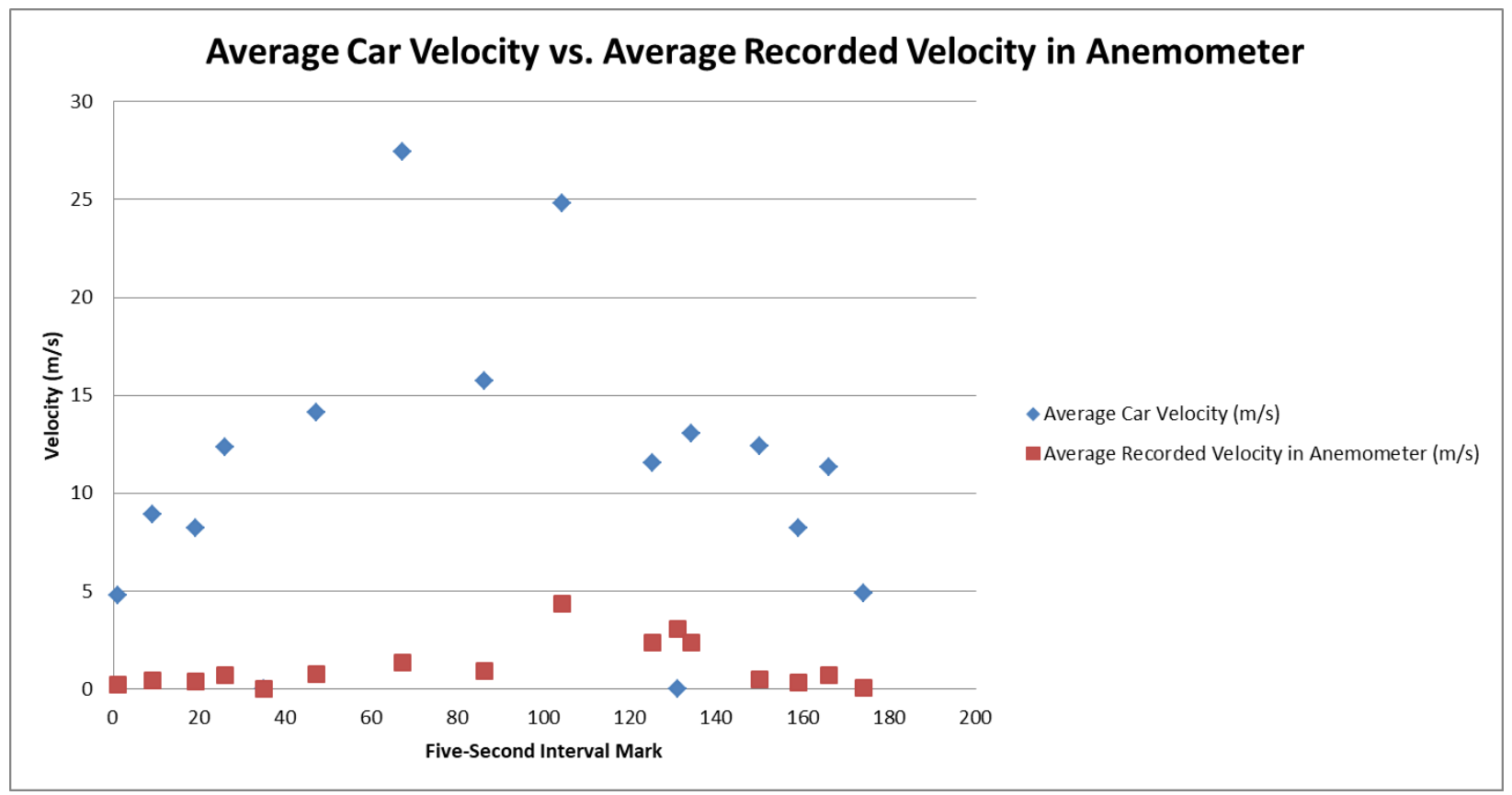

Figure 4: Average car velocity $(\mathrm{m} / \mathrm{s})$ vs. average recorded velocity in the anemometer $(\mathrm{m} / \mathrm{s})$

In addition to the average car velocities and average captured air velocities in each section of the test drive, Figure 5 displays the instantaneous power generated in watts, based on the power generation equation and assumptions made for the air density, area swept by the blades, and power coefficient [6], during each data reading taken. The power generated is directly proportional to the velocity recorded in the anemometer by a cubed factor, which corresponds to the velocity input of the power generation equation. With the power calculations recorded, they were then averaged to show average power generated per square meter, which is identical to average energy generated per second per square meter $\left(\mathrm{Ws} / \mathrm{m}^{2} \mathrm{~s}\right)$.

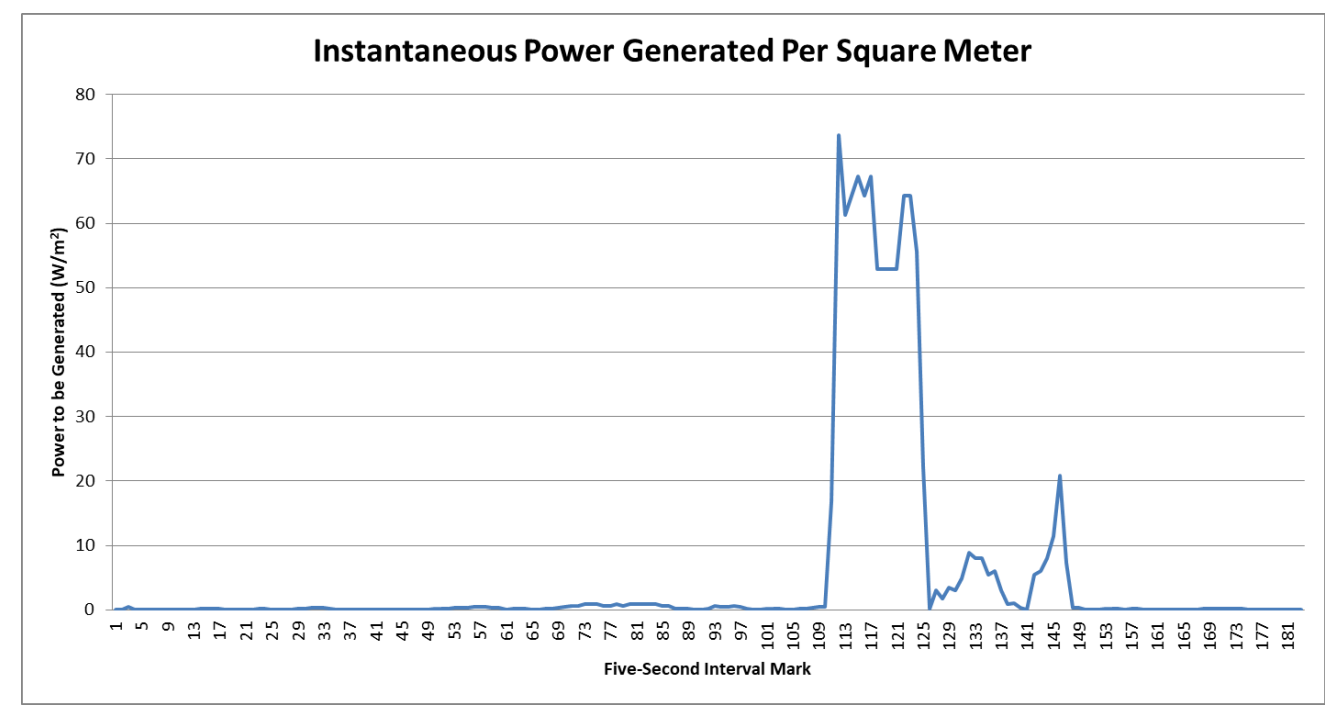

Figure 5: Instantaneous power generated on a square meter basis $\left(\mathrm{W} / \mathrm{m}^{2}\right)$ 
Figure 6 displays the average energy generated per second per square meter basis with respect to the car velocity. The majority of the points generated were insignificant as they showed little to no generation. Only four data values, which are complemented with an orange star on the graph, suggested that generated would increase with an increased car velocity. With these four points, a custom third-order equation through the origin was made. Even though this equation corresponds to only four data points, we concluded that the equation would best represent the results in the future with more data. The equation displays the energy output per square meter each second $\left(\mathrm{Ws} / \mathrm{m}^{2} \mathrm{~s}\right)$ as " $\mathrm{y}$ " when the car velocity in $\mathrm{mph}$ is the input as "x."

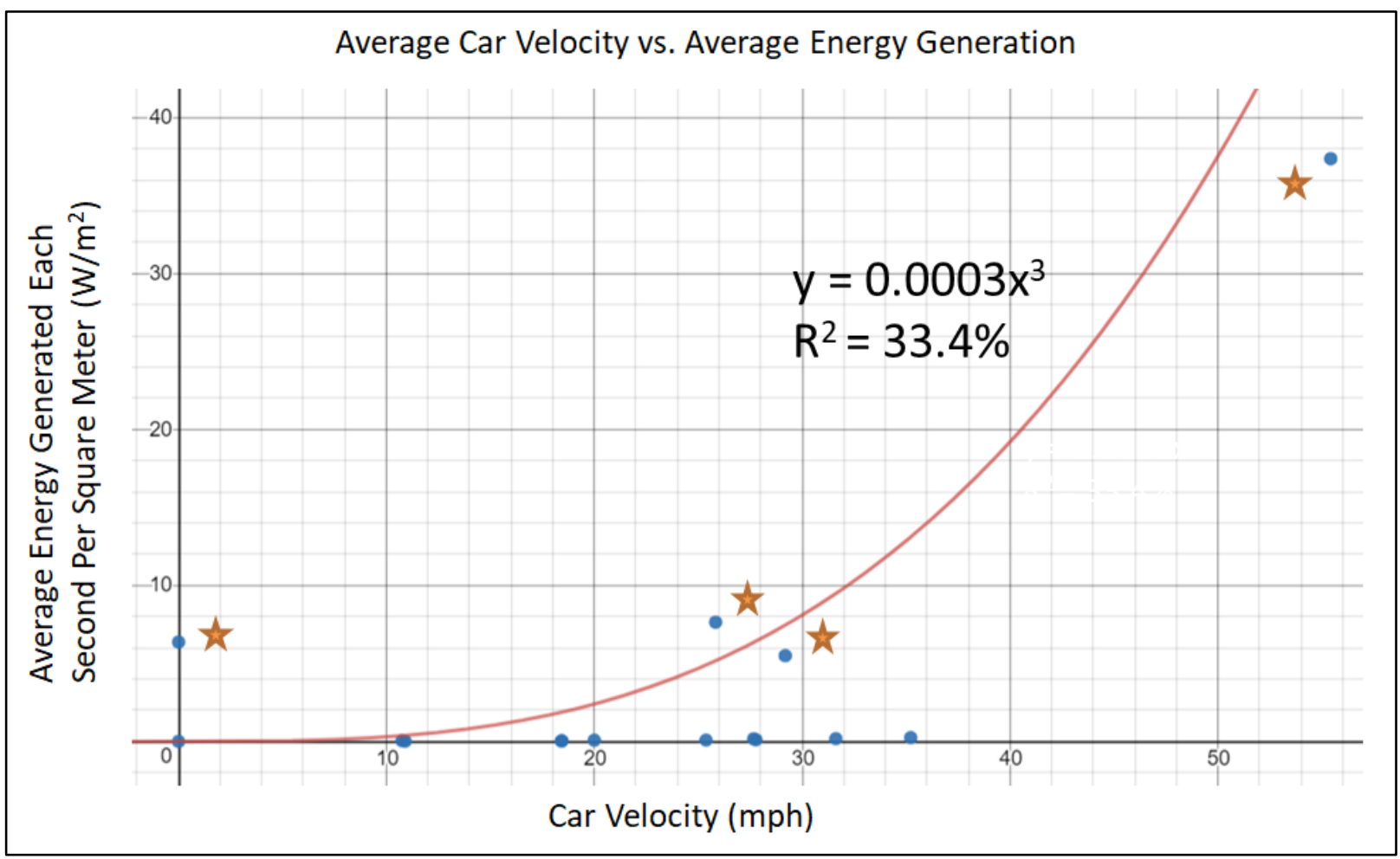

Figure 6: Average car velocity (mph) vs. average energy generation on a square meter basis $\left(\mathrm{W} / \mathrm{m}^{2}\right)$

\section{Discussion}

The finding shows that as the car velocity went up, so did the anemometer record, but the results were highly inconsistent. For instance, intervals 67-85 and 104-124 were both recorded on the same $65 \mathrm{mph}$ highway between the same exits but in opposite directions. In the first section, the average anemometer reading was $1.37 \mathrm{~m} / \mathrm{s}$ whereas the second section gave a 4.38 $\mathrm{m} / \mathrm{s}$ average. Some possibilities for the discrepancy could have been the direction of the wind, leaves blocking the airflow, or other weather patterns that could not be controlled. Additionally, the location in the compartment where the anemometer was mounted may not have necessarily been the best for consistent airflow. A detailed test to analyze air particle motion through the 
compartment while driving was not taken, so the location in front of the air flap was chosen based on fitting space, mounting ease with zip ties and painters tape, and an estimated consistency of airflow. Finally, the single test drive done is highly subjective to a number of uncontrolled variables such as weather conditions, time spent at stoplights and stop signs, driving speed based on traffic, elevation gains, and so on. These factors could be controlled in a wind tunnel and with more tests to give more consistent results.

In addition to the test drive results displayed in Figure 3 and condensed in Figure 4, Figure 5 shows the theoretical power that could be generated on a square meter basis. For the majority of the test, the power generated is less than one Watt per meter squared, which is largely due to the anemometer recording being close to one meter per second for the majority of the test drive. However, when the recorded velocity reached near 4.38 meters per second from intervals 104-124, the power generated increased by a factor of approximately sixty-four, which results in a significant spike in the amount of power that can be produced. The increase helps to explain how the amount of energy generated can significantly increase on long road trips with more use of freeways versus local trips with minimal freeway use. Such an increase in energy generation is illustrated in Figure 6 with an equation relating energy output per second on a square meter basis when the driving speed, in $\mathrm{mph}$, is the input. With only four significant data points, the custom third-order equation through the origin is also highly subjective to change with more significant data points as well as a better fit for a higher coefficient of determination. Regardless, the equation suggests that the turbine-generator system would be most reliable at higher driving speeds.

With the equation created, the energy output of the theoretical system was then evaluated for potential economic benefits. An estimated cost of $\$ 50$ was given for a system to include a fan blade, generator, wires, and so on. However, given that the system cost could highly fluctuate, an analysis was done to find out how many seconds of driving at a fixed speed it would take to make up each individual dollar that the system would cost. First, the average cost of a $\mathrm{kWh}$ in the United States is 13.19 cents [7], which equates to $7.7 \mathrm{kWh}$ per dollar. For the experiment, generating $7.7 \mathrm{kWh}$ on a square meter basis can then be divided by the third-order equation relating driving speed and energy generation for a new equation to relate a fixed driving speed, $\mathrm{v}$, in mph to the amount of seconds needed to make up one dollar that the system costs.

$$
\operatorname{Time}(s)=\frac{\left(7.7 \frac{\mathrm{kWh}}{\mathrm{m}^{2}} * \frac{1000 \mathrm{~W}}{1 \mathrm{~kW}} * \frac{3600 \mathrm{~s}}{1 \mathrm{~h}}\right)}{0.0003 v^{3} \frac{\mathrm{W}}{\mathrm{m}^{2}}}=\frac{9.24 * 10^{10}}{v^{3}} \mathrm{~s}
$$

With this equation, if the system cost is $\$ 50$ and the vehicle is traveling at $50 \mathrm{mph}$, it would take 427 days, or 1.2 years, of nonstop driving to make up the cost of the system. If traveling at $75 \mathrm{mph}$, it would take 126 days of nonstop driving. Realistically, the system would not be able to take up one full square meter of space in the vehicle's compartment and it would not be in use for months or years nonstop. Therefore, as per the experiment conducted, the 
amount of time needed would be significantly greater, which ultimately makes the system significantly inefficient in terms of charging time as well as cost when compared to conventional charging. However, it was still valuable to explore the idea of capturing drag energy in the compartment through an undergraduate research course as the maximum potential for the amount of energy that can be retained is still unknown.

\section{Conclusion}

The yearlong project provided both the student and faculty mentors the opportunity to experiment how energy can be harvested inside an electric vehicle. The course also provided an opportunity for the student to better understand how to prepare and conduct research experiments.

Based on the experiment results as well as the time needed for the system to pay for itself, the theoretical wind-turbine system for capturing wasted drag energy in the vehicle's compartment would be highly impractical for commercial purposes due to its low rate of energy generation, dependency on longer times of freeway use, and high cost. However, there is significant room for innovation to make the system more efficient in terms of energy generation as well as improving the accuracy of the results through controlled variables. As an initial gap to fill the void of capturing drag energy in a commercial vehicle with a research course, it was expected that the energy output would be low because of the limited space for a turbine and generator in the compartment and a low coefficient of performance. On the other hand, the velocities captured in the anemometer had a significant role when they spiked above four meters per second as they significantly increased the power output. For more accurate results, more test drives should have been conducted to account for the multiple weather and driving conditions that could have been altered, which could result in more consistent and higher average anemometer readings.

As a theoretical trip scenario where this system could be implemented, the Athens Shuttle Service in Athens, GA has vehicles that travel between Athens and the Hartsfield-Jackson Atlanta International Airport about three times a day individually. The application was chosen due to its high freeway use, which has about 10 minutes of in-town travel of about $40 \mathrm{mph}$ and 80 minutes on the highway at about $70 \mathrm{mph}$. Instead of having one large fan sweeping one square meter, it would be possible to have up to three small fans of $10 \mathrm{~cm}$ radii. With those numbers and the equations generated from the experiment, the vehicle would be able to make up just over one cent of the system's cost every day, and about 97 days to make up 1 dollar. Therefore, if the system's production cost was $\$ 50$, it would take about 13.3 years before the costs are entirely made up. 
Moving Forward

For future work in an undergraduate research course, a better understanding of how much drag energy can be captured in a vehicle's compartment can be found through a lab-controlled experiment rather than a real-world experiment. For example, a wind tunnel test could be performed for controlled airflow as well as controlled environmental conditions, which would create more accurate and consistent results. Additionally, a wind tunnel test could help to identify locations within the compartment with the greatest airflow for installing a turbinegenerator system rather than visually picking a location for mounting. Lastly, other hybrid and electric vehicles could be tested on rather than the 2017 Ford C-Max Plug-In Hybrid for potential drag energy to be captured.

Even though the system would be ineffective based on the conducted experiment, there are a significant number of ways to increase the amount of energy generated by the system, which can be explored in future research courses. First, instead of mounting a pre-made anemometer and generator into a vehicle's compartment, such a system can be integrated into the compartment's design, which would also create more room for the turbine blades to sweep. Also, a similar system could be made to have the turbine be placed outside the vehicle for much greater airflow. However, one issue with doing so would be increased drag generated, as shown by harvesting wind energy on the exterior of trains [8]. On the other hand, the cost of higher aerodynamic resistance could be compared with the increased energy generated as a trade-off. Finally, the compartment may not necessarily be the best location to capture wasted drag energy. Experiments can be conducted to capture drag within air-conditioning systems, exhaust systems, etc. that may prove to be more cost-effective than capturing drag energy in the compartment. For further analysis, the theoretical turbine-generator system could also be experimented in multiple modes of transportation including jets, boats, and submarines to analyze how fluid flow could increase the amount of power that these vehicles consume.

\section{References}

1. University of Georgia. 12 March, 2020, https://curo.uga.edu/.

2. Luthi, D. (2019). Climate Change Evidence: How Do We Know? NASA, NASA, 30 Dec. 2019, climate.nasa.gov/evidence/.

3. EPA, Environmental Protection Agency, 10 May 2018. Greenhouse Gas Emissions from a Typical Passenger Vehicle. www.epa.gov/greenvehicles/greenhouse-gas-emissionstypical-passenger-vehicle. 
4. Sindhuja, B. (2014). A Proposal for Implementation of Wind Energy Harvesting System in Trains. Proceedings of The 2014 International Conference on Control, Instrumentation, Energy and Communication (CIEC), 2014, doi:10.1109/ciec.2014.6959180.

5. Dwyer Instruments (2017). Model VT-300 Miniature Vane Thermo-Anemometer. Model VT-300 | Miniature Vane Thermo-Anemometer Measures Air Velocity, Air Volume, Temperature, and Humidity inside Air Ducts. Application in HVAC. www.dwyerinst.com/Product/TestEquipment/VaneThermo-Anemometer/ModelVT300/Google?gclid=CjwKCAjw1ZbaBRBUEiwA4VQCIfxiow_1kE1xhJwVBc3vNxe6Tq mlv1kFmSUIpgKj8ag2tRqMio-28BoCVawQAvD_BwE.

6. Trewby, J. (2007). Wind Turbine Power Calculations. The Royal Academy of Engineering, 2007.

7. Eisenbach Consulting, LLC (Jan, 2020). Electricity Rates by State (Updated January 2020)." Electric Choice. www.electricchoice.com/electricity-prices-by-state/.

8. Nurmanova, Venera, et al. (2017). Feasibility Study on Wind Energy Harvesting System Implementation in Moving Trains. Electrical Engineering, vol. 100, no. 3, 13 Nov. 2017, pp. 1837-1845., doi:10.1007/s00202-017-0664-6. 